\title{
Pattern and Atherogenic Index of Dyslipidaemia among Hypertensive Patients
}

\section{Umuerri E.M.}

\begin{abstract}
Objective: To describe the prevalence, pattern and atherogenic index of dyslipidaemia among hypertensive patients.

Method: Cross-sectional study of hypertensive subjects at first presentation in a community-based cardiology clinic in Delta State, Nigeria. The Delta State University Teaching Hospital Health Research Ethics Committee granted ethical approval for the study. Fasting serum lipid profile was retrieved and atherogenic indices calculated. Data analysis was done using SPSS version 23.0.
\end{abstract}

Result: The mean age of the 227 subjects was $55.4( \pm 13.6)$ years, and $111(48.9 \%)$ were males. A total of 154 $(67.8 \%)$ had at least one abnormal lipid profile level, out of which $56.5 \%$ were females $(\mathrm{p}=0.018)$. The pattern of dyslipidaemia [isolated $(56,36.4 \%)$, two-combined $(65,42.2 \%)$, and mixed $(33,21.4 \%)$ ] did not differ by sex (p $=0.173)$.

The predisposition to high cardiovascular risk was predicted by atherogenic index of plasma (59.5\%), atherogenic coefficient (43.6\%), Castelli ratios I, II (29.1\%, 26.9\%).

Conclusion: The prevalence of dyslipidaemia was $67.8 \%$. Two-combined dyslipidaemia was the most common pattern.

Keywords: Dyslipidaemia, atherogenic index, hypertension, prevalence, Nigeria

Department of Medicine, Faculty of Clinical Sciences, Delta State University, Abraka, Nigeria.

Delta State University Teaching Hospital, Oghara, Nigeria

Orcid ID: 0000-0001-8372-8328

E-mail: umuerriejiro@gmail.com 


\section{Schéma et indice athérogène de la dyslipidémie chez les patients hypertendus}

\section{Umuerri E.M.}

\section{Résumé}

Objectif de l'étude: Décrire la prévalence, le profil et l'indice athérogène de la dyslipidémie chez les patients hypertendus

Méthode de l'étude: Étude transversale de sujets hypertendus lors de la première présentation dans une clinique de cardiologie communautaire dans l'État du Delta, au Nigéria. Le comité d'éthique de la recherche sur la santé de l'hôpital universitaire de l'État du Delta a accordé une approbation éthique à l'étude. Le profil lipidique sérique à jeun a été récupéré et les indices athérogènes calculés. L'analyse des données a été effectuée à l'aide de la version 23.0 de SPSS.

Résultat de l'étude : L'âge moyen des 227 sujets était de 55,4 $( \pm 13,6)$ ans et $111(48,9 \%)$ étaient des hommes. Un total de $154(67,8 \%)$ avaient au moins un niveau de profil lipidique anormal, dont 56,5\% étaient des femmes $(p=0,018)$. Le profil de la dyslipidémie [isolée $(56,36,4 \%)$, bi-combinée $(65,42,2 \%)$ et mixte $(33,21,4 \%)$ ] ne différait pas selon le sexe $(\mathrm{p}=0,173)$. La prédisposition à un risque cardiovasculaire élevé était prédite par l'indice athérogène du plasma $(59,5 \%)$, le coefficient athérogène $(43,6 \%)$, les rapports de Castelli I, II (29,1\%, $26,9 \%)$.

Conclusion: La prévalence de la dyslipidémie était de 67,8\%. La dyslipidémie à deux combinaisons était le schéma le plus courant.

Mots-clés: Dyslipidémie, indice athérogène, hypertension, prévalence, Nigéria

Department of Medicine, Faculty of Clinical Sciences, Delta State University, Abraka, Nigeria.

Delta State University Teaching Hospital, Oghara, Nigeria

Orcid ID: 0000-0001-8372-8328

E-mail: umuerriejiro@gmail.com 


\section{MATERIALS AND METHOD}

This cross-sectional study was carried out at a community-based cardiology clinic in Sapele, Delta State, Nigeria. A formal ethics approval to conduct the study was obtained from the Health Research Ethics Committee of the Delta State University Teaching Hospital (HREC/PAN/2019/048/0319).

The medical records of all the patients with systemic hypertension who presented for the first time to the clinic within the past 5 years were manually retrieved. The record of patients with hypertension who were aged less than 18 years, had a working diagnosis of secondary hypertension and those with incomplete or no documented fasting serum lipid profile (total cholesterol, triglyceride, high density lipoproteins and low density lipoproteins) results were excluded from the study.

The age, sex, anthropometric indices, and laboratory data extracted from the case notes were documented in a structured data collection sheet. The weight in kilograms $(\mathrm{kg})$ and height in metres $(\mathrm{m})$ of the patients were also retrieved from the case notes. The body mass index (BMI) computed thereafter in $\mathrm{kg} / \mathrm{m}^{2}$ and categorized as underweight $(<18.5)$, normal weight (18.5-24.9), overweight (25.0-29.9) and obese $(\geqslant 30.0)$. The fasting blood glucose, fasting serum lipid profile [total cholesterol (TC), highdensity lipoprotein cholesterol (HDL), low-density lipoprotein cholesterol (LDL), triglyceride (TG)] levels during the initial evaluation of the patients were documented. The atherogenic index and lipid ratios were calculated from the serum lipid profile parameters.

\section{DEFINITIONS}

\section{Dyslipidaemia}

Dyslipidaemia was defined using the third report of the National Cholesterol Education Programme expert panel on detection, evaluation, and treatment of high blood cholesterol in adults (NCEP ATP III) (14). Optimal/desirable fasting lipid profile levels were total cholesterol $<200 \mathrm{mg} / \mathrm{dl}$, LDL $<100 \mathrm{mg} / \mathrm{dl}$, $\mathrm{HDL}>40 \mathrm{mg} / \mathrm{dl}$ for males, $>50 \mathrm{mg} / \mathrm{dl}$ for females and serum TG $<150 \mathrm{mg} / \mathrm{dl}$. Levels of TC $\geqslant 200 \mathrm{mg} / \mathrm{dl}$, $\mathrm{LDL} \geqslant 130 \mathrm{mg} / \mathrm{dl}$ and $\mathrm{TG} \geqslant 150 \mathrm{mg} / \mathrm{dl}$ were elevated while HDL $\leqslant 40 \mathrm{mg} / \mathrm{dl}$ and $\leqslant 50 \mathrm{mg} / \mathrm{dl}$ were low for males and females, respectively.

\section{Pattern of dyslipidaemia}

The pattern of dyslipidaemia was defined as isolated single parameter, combined two parameters or mixed dyslipidaemia. Isolated dyslipidaemia is defined as elevated TC, LDL, TG or low HDL occurring in isolation with the other parameters within normal range. Two-combined parameter dyslipidaemia implies combination of any two of the serum lipid profile abnormality. For example, high TC and TG, high TC and low HDL, high TG and LDL. Mixed dyslipidaemia is a combination of any three or all four abnormal serum lipid profile parameters.

\section{Atherogenic Indices}

The atherogenic index of plasma (AIP) was defined as the logarithm of the ratio TG and HDL $\left(\log _{10}\right.$ TG/HDL). AIP values less than 0.1 are associated with low cardiovascular risk while values between $0.1-0.24$, and $>0.24$ are associated with medium and high cardiovascular risk, respectively (15).

The Castelli's risk index (CRI) was defined as the ratio of TC and HDL (CRI-I) and the ratio of LDL and HDL (CRI-II). Increased cardiovascular risk is associated with CRI-I values $>5.0$ and $>4.5$ in male and females, respectively $(10,16)$ and CRI-II values $>3.5$ and $>3.0$ in male and females, respectively (17).

The atherogenic coefficient (AC) was defined as the ratio of the difference of TC and HDL and HDL; ([TC-HDL]/HDL). A value greater than 3.0 was considered to be abnormal (3).

\section{Data Analysis}

The data obtained were keyed into the Microsoft Excel spreadsheet before exporting to the Statistical Product and Service Solutions (SPSS) version 23.0 software (SPSS Inc, Chicago, Illinois, USA) for analysis. Descriptive and inferential analyses of the variables were performed with $p$-value $<0.05$ as significant. The categorical variables were summarized as frequency and percentages. The continuous variables were described by calculating the means and standard deviation (SD). The independent $t$-test was used to assess the difference between means. The association between categorical variables was analysed using Chi-square test. 


\section{RESULTS}

A total of 227 subjects met the study criteria out of which $111(48.9 \%)$ were males. The age range of the subjects was $27-91$ years with a mean (SD) age of $55.4( \pm 13.6)$ years. Table 1 shows the clinical characteristics of the subjects. Compared to males, female subjects had significantly higher mean body mass index (BMI) (28.6 vs $30.8 \mathrm{~kg} / \mathrm{m}^{2}, \mathrm{p}=0.009$ ). Although the mean total cholesterol (TC), high density lipoprotein (HDL) and low-density lipoprotein (LDL) in females were higher than males, the difference was only significant for HDL ( $p=$ $0.015)$. The male subjects had a significantly higher mean atherogenic index of plasma (AIP) (0.33 vs $0.25, \mathrm{p}=0.009$ ).

Of the 227 subjects studied, 154 had at least one abnormal lipid profile level. Thus, the overall prevalence of dyslipidaemia in this study was $67.8 \%$. A total of 73 (32.2\%) subjects had no form of lipid abnormality. Table 2 shows the distribution of lipid abnormality in the index study. A significantly higher proportion of the subjects with dyslipidaemia were females, $56.5 \%$ vs $43.5 \%,\left(\chi^{2}=5.572, \mathrm{df}=1, \mathrm{p}=\right.$ 0.018).

Of the 154 subjects with abnormal lipid profile, 56 had isolated dyslipidaemia, 65 had two-combined dyslipidaemia and 33 had mixed dyslipidaemia. (figure 1)
Low HDL was the most common form of isolated dyslipidaemia in this study. It accounted for $64.2 \%$ $(36 / 56)$ of all forms of isolated dyslipidaemia and $23.4 \%$ of total dyslipidaemia. (Table 3 ) The most frequent form of two-combined dyslipidaemia was high TC and high LDL, accounting for $67.7 \%(44 / 65)$ of this form of dyslipidaemia and $28.6 \%$ of total dyslipidaemia. (Table 3) The combination of high TC, high LDL and low HDL was the commonest form of mixed dyslipidaemia. (Table 3). The pattern of dyslipidaemia observed in this study did not differ significantly by $\operatorname{sex}\left(\chi^{2}=15.202, d f=11, p=0.173\right)$.

Table 4 shows the distribution of predicted cardiovascular risk profile using the atherogenic indices. The predisposition to high cardiovascular risk was mostly predicted by AIP (59.5\%). The prevalence of predicted high cardiovascular risk using CRI-I, CRI-II and AC were 29.1\%. 26.9\% and $43.6 \%$, respectively. Using AC, male subjects had a significantly higher cardiovascular risk $(56.6 \%$ vs $43.4 \%, p=0.042$ ). The other atherogenic indices did not differ significantly between sexes.

All the subjects with predicted high CVD risk had dyslipidaemia using the Castelli Risk Index (CRI-I and CRI-II). (Table 4) On the contrary, $21.5 \%$ of the subjects with high CVD risk predicted by AIP did not have any form of dyslipidaemia. (Table 4)

Table 1: Clinical characteristics of subjects

\begin{tabular}{llllll}
\hline Variable & \multicolumn{1}{c}{ Mean $( \pm$ SD) } & $\mathbf{9 5 \%}$ CI & p-value \\
\cline { 2 - 5 } & $\begin{array}{l}\text { Total } \\
(\mathbf{n}=\mathbf{2 2 7})\end{array}$ & $\begin{array}{l}\text { Male } \\
(\mathbf{n}=\mathbf{1 1 1})\end{array}$ & $\begin{array}{l}\text { Female } \\
(\mathbf{n}=\mathbf{1 1 6})\end{array}$ & & \\
\hline Age $(\mathrm{years})$ & $55.4(13.6)$ & $56.0(14.5)$ & $54.9(12.8)$ & -2.513 to 4.614 & 0.562 \\
BMI $\left(\mathrm{kg} / \mathrm{m}^{2}\right)$ & $29.8(5.5)$ & $28.6(4.6)$ & $30.8(6.1)$ & -3.906 to -0.560 & $\mathbf{0 . 0 0 9}$ \\
SBP $(\mathrm{mmHg})$ & $156.0(27.3)$ & $155.6(27.0)$ & $156.6(27.7)$ & -8.317 to 6.259 & 0.781 \\
DBP $(\mathrm{mmHg})$ & $92.9(15.1)$ & $94.3(15.8)$ & $91.6(14.4)$ & -1.390 to 6.646 & 0.199 \\
FBG $(\mathrm{mg} / \mathrm{dl})$ & $105.5(41.2)$ & $109.0(44.5)$ & $102.4(38.0)$ & -5.628 to 18.788 & 0.289 \\
TC $(\mathrm{mg} / \mathrm{dl})$ & $197.1(54.7)$ & $192.2(55.9)$ & $201.8(53.3)$ & -23.877 to 4.705 & 0.188 \\
HDL $(\mathrm{mg} / \mathrm{dl})$ & $50.4(14.6)$ & $48.1(14.0)$ & $52.7(14.8)$ & -8.456 to -0.905 & $\mathbf{0 . 0 1 5}$ \\
LDL $(\mathrm{mg} / \mathrm{dl})$ & $124.9(47.4)$ & $118.8(43.4)$ & $130.8(50.4)$ & -24.347 to 0.303 & 0.056 \\
TG $(\mathrm{mg} / \mathrm{dl})$ & $103.8(46.2)$ & $109.0(53.1)$ & $98.8(38.0)$ & -1.851 to 22.204 & 0.097 \\
CRI-I & $4.17(1.51)$ & $4.29(1.58)$ & $4.05(1.44)$ & -0.165 to 0.625 & 0.252 \\
CRI-II & $2.72(1.39)$ & $2.74(1.42)$ & $2.70(1.37)$ & -0.331 to 0.397 & 0.859 \\
AC & $3.17(1.51)$ & $3.29(1.58)$ & $3.05(1.44)$ & -0.165 to 0.625 & 0.252 \\
AIP & $0.29(0.22)$ & $0.33(0.23)$ & $0.25(0.21)$ & 0.019 to 0.134 & $\mathbf{0 . 0 0 9}$
\end{tabular}

SD: Standard Deviation, CI: Confidence Interval, BMI: Body Mass Index, SBP: Systolic Blood Pressure, DBP: Diastolic Blood Pressure, FBS: Fasting Blood Glucose, TC: Total Cholesterol, HDL: High Density Lipoprotein, LDL: Low Density Lipoprotein, TG: Triglyceride, CRI-I: Castelli's risk index I, CRI-II: Castelli's risk index II, AC: Atherogenic Coefficient, AIP: Atherogenic Index of Plasma 
Table 2: Distribution of abnormal lipid profile among subjects

\begin{tabular}{lllll}
\hline Variable & $\begin{array}{l}\text { Total (\%) } \\
\mathbf{n = 2 2 7}\end{array}$ & $\begin{array}{l}\text { Male (\%) } \\
\mathbf{n = 1 1 1}\end{array}$ & $\begin{array}{c}\text { Female (\%) } \\
\mathbf{n}=\mathbf{1 1 6}\end{array}$ & p-value \\
\hline High TC & $93(41.0)$ & $42(37.8)$ & $51(44.0)$ & 0.348 \\
Low HDL & $77(33.9)$ & $27(24.3)$ & $50(43.1)$ & $\mathbf{0 . 0 0 3}$ \\
High LDL & $90(39.6)$ & $44(39.6)$ & $46(39.7)$ & 0.998 \\
High TG & $30(13.2)$ & $18(16.2)$ & $12(10.3)$ & 0.192 \\
\hline
\end{tabular}

TC: Total Cholesterol, HDL: High Density Lipoprotein, LDL: Low Density

Lipoprotein, TG: Triglyceride

Table 3: Distribution of specific forms of dyslipidaemia

\begin{tabular}{lllrr}
\hline $\begin{array}{l}\text { Pattern of } \\
\text { Dyslipidaemia }\end{array}$ & Category & $\begin{array}{l}\text { Total (\%) } \\
\mathbf{n = 1 5 4}\end{array}$ & $\begin{array}{r}\text { Male (\%) } \\
\mathbf{n = 6 7}\end{array}$ & $\begin{array}{r}\text { Female (\%) } \\
\mathbf{n}=\mathbf{8 7}\end{array}$ \\
\hline Isolated & High TC & $11(7.1)$ & $2(3.0)$ & $9(10.3)$ \\
dyslipidaemia & High TG & $5(3.9)$ & $5(7.5)$ & $1(1.1)$ \\
& High LDL & $3(1.9)$ & $2(3.0)$ & $1(1.1)$ \\
& Low HDL & $36(23.4)$ & $12(17.9)$ & $24(27.6)$ \\
Two-combined & High TC + High TG & $3(1.9)$ & $2(3.0)$ & $1(1.1)$ \\
dyslipidaemia & High TC + High LDL & $44(28.6)$ & $22(32.8)$ & $22(25.3)$ \\
& High TC + Low HDL & $2(1.3)$ & $0(0.0)$ & $2(2.3)$ \\
& High TG + Low HDL & $6(3.9)$ & $2(3.0)$ & $4(4.6)$ \\
& High LDL + Low HDL & $10(6.5)$ & $4(6.0)$ & $6(6.9)$ \\
Mixed & High TC + High TG + & $5(3.2)$ & $2(3.0)$ & $3(3.4)$ \\
Dyslipidaemia & High LDL + Low HDL & & $7(10.4)$ & $11(12.6)$ \\
& High TC + High LDL + & $18(11.7)$ & & \\
& Low HDL & & & \\
& High TC + High TG + & $10(6.5)$ & & \\
\hline
\end{tabular}

TC: Total Cholesterol, HDL: High Density Lipoprotein, LDL: Low Density Lipoprotein, TG: Triglyceride

Table 4: Atherogenic indices' cardiovascular disease risk prediction by sex and presence of dyslipidaemia

\begin{tabular}{lllllll}
\hline $\begin{array}{l}\text { Atherogenic } \\
\text { Index }\end{array}$ & CVD Risk & Total (\%) & \multicolumn{2}{c}{ Sex } & \multicolumn{2}{c}{ Dyslipidaemia } \\
\cline { 4 - 7 } & & N= 227 & Male & Female & Absent & Present \\
\hline CRI-I & Low Risk & $161(70.9)$ & $81(50.3)$ & $80(49.7)$ & $73(45.3)$ & $88(54.7)$ \\
& High Risk & $66(29.1)$ & $30(45.5)$ & $36(54.5)$ & $0(0.0)$ & $66(100.0)$ \\
CRI-II & & & $\mathrm{p}=0.506$ & & $\mathrm{p}<0.001$ & \\
& Low Risk & $166(73.1)$ & $84(50.6)$ & $82(49.4)$ & $73(44.1)$ & $93(56.0)$ \\
& High Risk & $61(26.9)$ & $27(44.3)$ & $34(55.7)$ & $0(0.0)$ & $61(100.0)$ \\
AC & & & $\mathrm{p}=0.397$ & & $\mathrm{p}<0.001$ & \\
& Low Risk & $128(56.4)$ & $55(43.0)$ & $73(57.0)$ & $67(52.3)$ & $61(47.7)$ \\
& High Risk & $99(43.6)$ & $56(56.6)$ & $43(43.4)$ & $6(6.1)$ & $93(93.9)$ \\
AIP & & & $\mathrm{p}=0.042$ & & $\mathrm{p}<0.001$ & \\
& Low Risk & $45(19.8)$ & $16(35.6)$ & $29(64.4)$ & $27(60.0)$ & $18(40.0)$ \\
& Medium Risk & $47(20.7)$ & $26(55.3)$ & $21(44.7)$ & $17(36.2)$ & $30(63.8)$ \\
& High Risk & $135(59.5)$ & $69(51.1)$ & $66(48.9)$ & $29(21.5)$ & $106(78.5)$ \\
\hline
\end{tabular}

CVD: cardiovascular Disease, CRI-I: Castelli's risk index I, CRI-II: Castelli's risk index II, AC: Atherogenic Coefficient, AIP: Atherogenic Index of Plasma 




Figure 1: Pattern of dyslipidaemia

\section{DISCUSSION}

The prevalence of dyslipidaemia among patients with hypertension in this study was high. Two out of every three subjects had at least one abnormal lipid profile parameter. This finding substantiates the fact that cardiovascular risk factors often coexist in clusters; dyslipidaemia and hypertension in this instance. Similar to this study, previous studies in Nigeria also reported high prevalence rates of dyslipidaemia among patients with hypertension $(8,18-20)$. The prevalence of dyslipidaemia among newly presenting hypertensive patients in a hospital-based study in North Central Nigeria was 64\% (18). Akintunde et al reported an overall prevalence of dyslipidemia of $58.9 \%(96 / 163)$ among newly diagnosed Nigerian hypertensive subjects in South West Nigeria (8). In a hospital-based study of elderly patients with hypertension in South East Nigeria, Iloh et al reported an overall prevalence of dyslipidaemia of $44.3 \%(54 / 122)$ (18). In a community-based study of 413 newly diagnosed hypertensives in South West Nigeria, Olamoyegun et al reported an overall prevalence of dyslipidaemia of $74.9 \%$ (19).

The two-combined dyslipidaemia (42.2\%) was the most common pattern observed in this study, followed by isolated dyslipidaemia (36.4\%), and lastly, mixed dyslipidaemia (21.4\%). Akintunde et al however, reported a higher prevalence of isolated dyslipidaemia (41.1\% vs $36.4 \%$ ) (8). Low HDL was the most prevalent isolated dyslipidaemia in this study. This pattern is reported by other Nigerian based studies among patients with hypertension $(8,9$, 18-21)and in the general population (5-7).

The atherogenic indices used to predict cardiovascular disease risk performed differently in this study. The atherogenic index of plasma (AIP) predicted high cardiovascular disease risk among more subjects compared to atherogenic coefficient and Castelli risk index. Although relatively novel, AIP is a better biomarker of atherosclerotic cardiovascular disease than other lipid ratios $(22,23)$. It has been shown to be a strong and independent predictor of coronary artery disease $(24,25)$.

\section{CONCLUSION}

The prevalence of dyslipidaemia in this study was high. The pattern of dyslipidaemia observed in descending order of frequency were two-combined, isolated, and mixed dyslipidaemia. Low HDL and combined high TC and high LDL were the most prevalent forms of isolated and two-combined dyslipidaemia, respectively. AIP's prediction of high cardiovascular disease risk was twice that of the Castelli ratios (CRI-I and CRI-II). Fasting serum lipid profile should be routinely performed among patients with hypertension, and AIP should preferably be the atherogenic index used to predict cardiovascular disease risk.

\section{CONFLICT OF INTEREST}

No conflict of interest 


\section{REFERENCES}

1. Noubiap JJ, Bigna JJ, Nansseu JR, Nyaga UF, Balti EV, Echouffo-Tcheugui JB, et al. Prevalence of dyslipidaemia among adults in Africa: a systematic review and meta-analysis. Lancet Glob Health 2018;6:E998-E1007. Doi: 10.1016/S2214-109X(18) 30275-4

2. Karaye KM, Habib AG. Dyslipidaemia in patients with established cardiovascular disease in subSaharan Africa: A systematic review and metaanalysis. Eur J Prev Cardiol 2014;21(6):682-691. Doi: $10.1177 / 20147487312460018$

3. Olamoyegun MA, Oluyombo R, Asaolu SO. Evaluation of dyslipidaemia, lipid ratios, and atherogenic index as cardiovascular risk factors among semi-urban dwellers in Nigeria. Ann Afr Med 2016;15:194-199. Doi: 10.4103/1596-3519.194280

4. Oguejiofor OC, Onwukwe CH OC. Dyslipidemia in Nigeria: Prevalence and pattern. Ann Afr Med 2012;11(4):197-202

5. Sani MU, Wahab KW, Yusuf BO, Gbadamosi M, Johnson OU, Gbadamosi A. Modifiable cardiovascular risk factors among apparently healthy adult Nigerian population-a cross sectional study. BMC Research notes 2010;3:11

6. Osuji CU, Nzerem BA, Meludu S, Dioka CE, Nwobodo E, Amilo GI. The prevalence of overweight/obesity and dyslipidaemia amongst a group of women attending "August" meeting. Niger Med J 2010;51:155-9

7. Odenigbo CU, Oguejiofor OC, Odenigbo UM, Ibeh $\mathrm{CC}$, Ajaero $\mathrm{CN}$, Odike MA. Prevalence of dyslipidaemia in apparently healthy professionals in Asaba, South South Nigeria. Nig J Clin Pract 2008; $11: 330-5$

8. Akintunde AA, Ayodele EO, Akinwusi OP OG. Dyslipidemia among newly diagnosed hypertensives: pattern and clinical correlates. J Natl MedAssoc 2010;102(5):403-7

9. Ojji DB, Ajayi SO, Mamven MH, Atherton J. Prevalence of dyslipidemia in normoglycemic subjects with newly diagnosed high blood pressure in Abuja, Nigeria. J Clin Lipidol 2009;3(1):51-6.

10. Ogbera AO, Fasanmade OA, Chinenye S, Akinlade A. Characterization of lipid parameters in diabetes mellitus - a Nigerian report. Int Arch Med 2009;2:19. Doi: 10.1186/1755-7682-2-19

11. Dalal JJ, Padmanabhan TNC, Jain P, Patil S, Vasnawala H, Gulati A. LIPITENSION: Interplay between dyslipidemia and hypertension. Indian $\mathrm{J}$ Endocrinol Metab. 2012;16(2):240-5. Doi:

\section{$10.4103 / 2230-8210.93742$}

12. Wong ND, Lopez V, Tang S WG. Prevalence, treatment, and control of combined hypertension and hypercholesterolemia in the United States. Am J Cardiol 2006;98(2):204-8. Doi: 10.1016/ j.amjcard.2006.01.079

13. Chapman MJ, Sposito AC. Hypertension and dyslipidaemia in obesity and insulin resistance: pathophysiology, impact on atherosclerotic disease and pharmacotherapy. Pharmacol Ther 2008;117(3):354-73. Doi: 10.1016/ j.pharmthera. 2007.10.004

14. Third report of the National Cholesterol Education Programme (NCEP) expert panel on detection, evaluation, and treatment of high blood cholesterol in adults (Adult Treatment Panel III) final report. Circulation 2002;106(25):3143-421

15. Dobiásová M. AIP-Atherogenic index of plasma as a significant predictor of risk: from research to practice. Vnitr Lek 2006;52(1):64-71

16. Understanding the cholesterol ratio. Available from: https://www.cholesterolmenu.com/cholesterolratio-castelli-index/ Last accessed on 20/04/2020

17. Millán J, Pintó X, Muñoz A, Zúñiga M, Rubiés-Prat J, Pallardo LF, et al. Lipoprotein ratios: Physiological significance and clinical usefulness in cardiovascular prevention. Vasc Health Risk Manag 2009;5:757-765

18. Adamu UG, Okuku GA, Oladele CO, Abdullahi A, Oduh JI, Fasae AJ. Serum lipid and correlates in newly presenting Nigerians with arterial hypertension. Vasc Health Risk Manag 2013;9:763768

19. Iloh GUP, Ofoedu JN, Amadi AN, Obikwu CE. The magnitude of atherogenic dyslipidaemia among geriatric Nigerians with systemic hypertension in a rural hospital in Eastern Nigeria. Niger $\mathrm{J}$ Med 2012;21:320-325

20. Olamoyegun AM, Fawale MB, Oluyombo R. The relationship between measures of obesity and atherogenic lipids among Nigerians with hypertension. Malawi Med J 2019;31:193-197. Doi: 10.4314/mmj.v31i3.5

21. Osuji CU, Omejua EG, Onwubuya EI, Ahaneku GI. Serum lipid profile of newly diagnosed hypertensive patients in Nnewi, South-East Nigeria. Int J Hypertens 2012;2012:710486

22. Niroumand S, Khajedaluee M, Khadem-Rezaiyan M, Abrishami M, Juya M, Khodaee G, et al. Atherogenic index of plasma (AIP): a marker of cardiovascular disease. Med J Islam Repub Iran 2015;29:240 
23. Khazaal MS. Atherogenic index of plasma as a parameter in predicting cardiovascular risk in males compared to the conventional dyslipidemic indices. Karbala J Med 2013;6:1506-1531

24. Zhan Y, Xu T, Tan X. Two parameters reflect lipiddriven inflammatory state in acute coronary syndrome: atherogenic index of plasma, neutrophil- lymphocyte ratio. BMC Cardiovasc Disord 2016;16:96

25. Gaojun C, Ganwei S, Sheliang X, Wei L. The atherogenic index of plasma is a strong and independent predictor of coronary artery disease in the Chinese Han population. Medicine 2017; 96:e8058. Doi:10.1097/MD.0000000000008058 